\title{
Perbandingan Hasil Pendapatan Usahatani Padi antar Kecamatan di Kabupaten Langkat
}

\section{The Comparison of Rice Farming Income Results Between Districts in Langkat Regency}

\author{
Ahmad Fajrin Sitompul'1), Sya'ad Afifuddin'2), E. Harso Khardinata'), Tumpal H.S. \\ Siregar ${ }^{4}$ \\ 1) Program Studi Magister Agribisnis, Pascasarjana, Universitas Medan Area, Indonesia \\ 2)Magister Ilmu Ekonomi, Universitas Sumatera Utara, Indonesia \\ 3) Departemen Agroekoteknologi, Fakultas Pertanian, Universitas Sumatera Utara, Indonesia \\ 4) Magister Agribisnis, Pascasarjana, Universitas Medan Area, Indonesia
}

\begin{abstract}
Abstrak
Sasaran utama pengembangan pertanian adalah untuk meningkatkan produksi pertanian dan pendapatan petani padi, oleh karena itu kegiatan sektor pertanian diupayakan untuk berjalan dengan lancar dengan meningkatkan produk pangan melalui intensifikasi, ekstensifikasi, dan diversifikasi pertanian yang diharapkan dapat meningkatkan standar hidup petani, memperluas peluang kerja bagi masyarakat masih tergantung pada sektor pertanian. Tingkat pendapatan petani secara umum dipengaruhi oleh beberapa komponen, yaitu: jumlah produksi, harga jual, dan biaya yang dikeluarkan oleh petani dalam pertanian mereka. Penelitian ini bertujuan untuk mengetahui berapa besar biaya, pendapatan, pendapatan, R/C Ratio, selisih pendapatan usahatani padi antar Kabupaten di Kabupaten Langkat. Data yang digunakan adalah data primer yang bersumber dari kelompok tiga petani padi di Kabupaten Secanggang, Kabupaten Sei Bingei, dan Kabupaten Batang Serangan. Setiap kecamatan diambil sebanyak enam belas kelompok tani dengan memberikan daftar kuesioner. Model penelitian adalah model kuantitatif dengan menggunakan teknik F-test menggunakan SPSS versi 16.0. Hasil penelitian menunjukkan bahwa terdapat perbedaan biaya, pendapatan, pendapatan, dan R / C Rasio usahatani padi sawah di Kabupaten Secanggang, Kabupaten Sei Bingei, dan Kabupaten Batang Serangan di Kabupaten Langkat.

Kata kunci: perbandingan, pendapatan, biaya, pendapatan, pertanian, padi sawah
\end{abstract}

\begin{abstract}
The main target of agricultural development is to increase agricultural production and income of rice farmers, therefore the activities of the agricultural sector are endeavored to run smoothly by increasing food products through intensification, extensification and diversification of agriculture which is expected to improve the standard of living of farmers, expand employment opportunities for the community still depends on the agricultural sector. The level of income of farmers in general is affected by several components, namely: the amount of production, selling prices, and costs incurred by farmers in their agriculture. To find out how much the cost, revenue, income, $R / C$ Ratio, the difference in rice farm income between the Districts in Langkat District. The data used are primary data sourced from the groups of three rice farmers in Secanggang District, Sei Bingei District, and Batang Serangan District. Each subdistrict was taken as many as sixteen farmer groups by giving a questionnaire list. The research model is a quantitative model using F-test techniques using SPSS version 16.0. The results showed that there were differences in costs, revenues, income, and $R$ / $C$ Ratio of lowland rice farming in Secanggang District, Sei Bingei District, and Batang Serangan District in Langkat Regency.

Keywords: comparison, income, cost, revenue, farming, lowland rice
\end{abstract}

How to Cite: Sitompul, A. F., S. Afifuddin, E. H. Khardinata, \& T. H. S. Siregar. (2020). Perbandingan Hasil Pendapatan Usahatani Padi antar Kecamatan di Kabupaten Langkat. Jurnal Ilmiah Magister Agribisnis, 2(1) 2020: 1-9,

*E-mail: harsokhrdhinata@uma.ac.id ISSN 2550-1305 (Online)

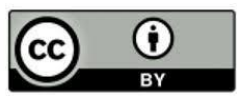




\section{PENDAHULUAN}

Era globalisasi menuntut kesiapan negara-negara di dunia menghadapi perdagangan bebas, termasuk Indonesia (Nuraini, 2016). Indonesia merupakan negara sedang berkembang dan memiliki wilayah daratan yang sangat luas dan didukung oleh stuktur geografis dan beriklim tropis yang sangat cocok untuk budidaya berbagai macam komoditas pertanian (Widayanto, 2007). Pertanian merupakan salah satu sektor yang diandalkan, karena sektor pertanian sampai saat ini masih memegang peranan penting dalam menunjang perekonomian nasional. (BPT Pertanian, 2009).

Sasaran utama pembangunan pertanian adalah peningkatan produksi pertanian dan pendapatan petani padi, karena itu kegiatan disektor pertanian diusahakan agar dapat berjalan lancar dengan peningkatan produk pangan baik melalui intensifikasi, ekstensifikasi dan diversifikasi pertanian yang diharapakan dapat memperbaiki taraf hidup petani, memperluas lapangan pekerjaan bagi golongan masyarakat yang masih tergantung pada sektor pertanian (Roidah, 2015). Peningkatan pendapatan dan produksi petani padi tidak terlepas dari proses pemeliharaan yang diberikan oleh tiap-tiap petani baik secara tradisional maupun modern (Supartama, 2013).

Peningkatan produksi merupakan tantangan yang terus menghadang dalam rangka penyediaan pangan penduduk yang terus meningkat populasinya (Widarto dan Susilo, 2004). Kebutuhan beras semakin tahun akan semakin meningkat sesuai dengan laju pertumbuhan penduduk dan perkembangan kondisi perekonomian masyarakat (Laksmi, 2012). Hal ini sejalan dengan pendapat (Lestari, 2012) bahwa permintaan akan beras terus meningkat seiring bertambahnya jumlah penduduk dan terjadinya perubahan pola makanan pokok pada beberapa daerah tertentu dari umbi-umbian keberas.

Tingkat pendapatan petani secara umum dipengeruhi oleh beberapa komponen yaitu : jumlah produksi, harga jual, dan biaya-biaya yang dikeluarkan petani dalam pertaniannya. Ini berarti bahwa perhatian pemerintah terhadap sektor pertanian merupakan usaha untuk memperbaiki taraf kehidupan sebagian besar penduduk yang tergolong miskin (Roidah, 2015). Salah satu upaya yang ditempuh adalah penerapan intensifikasi terutama pada lahan-lahan produktif. Sedangkan untuk lahan kering, rendahnya produktivitas lahan sebagai akibat laju erosi tanah serta rendahnya pendapatan petani yang merupakan kendala utama dalam pengembangan usahatani. Kedua masalah yang saling berkaitan tersebut perlu diatasi untuk mencapai usahatani yang berkesinambungan (Widarto dan Susilo, 2004). Usaha intensifikasi ini dilakukan dengan program panca usahatani yang meliputi: pemilihan bibit unggul, pengolahan lahan yang baik dan benar, pemakaian pupuk yang tepat, baik tepat jumlah maupun tepat waktu, pemberantasan hama penyakit (Widayanto, 2007).

Badan Pusat Statistik (2017), melaporkan bahwa produksi padi di Sumatra Utara pada tahun 2015 sebesar 75,40 juta ton gabah kering giling (GKG), naik 4,55 juta ton dibandingkan produksi tahun 2014. Kenaikan produksi diperkirakan terjadi karena peningkatan luas panen sebesar 14,12 juta hektar. Penyebab rendahnya produksi padi di Indonesia salah satunya karena pada umumnya petani masih membudidayakan padi tidak sesuai aturan, seperti pengolahan tanah dan pemberian takaran pupuk tidak sesuai dengan ketentuan yang dianjurkan serta masih mendominasinya petani mengunakan 
sistem konvensional (Lestari, 2012). Usaha peningkatan produksi padi ini diikuti oleh penyediaan penunjang produksi, salah satunya adalah ketersediaan pupuk. Penggunaan pupuk berimbang dalam usahatani padi sangat perlu dilakukan (Dewi, 2016).

Langkat merupakan salah satu Kabupaten di Sumatra Utara. Kabupaten Langkat terbagi menjadi 23 Kecamatan, Kecamatan yang menjadi objek penelitian adalah Kecamatan Secangang, Sei Bingei dan Batangan Serangan. Badan Pusat Statistik Kabupaten Langkat (2016) melaporkan bahwa produksi padi pada tahun 2016 di Kabupaten Langkat antar kecamatan memiliki hasil yang berbeda.

Upaya untuk meningkatkan produksi pertanian (padi) telah banyak dilakukan baik oleh pemerintah, lembaga swadaya masyarakat, dan perguruan tinggi. Tetapi didalam pelaksanaannya diperoleh fakta bahwa hasil potensial produksi padi berbeda dengan hasil nyata yang diperoleh petani. Perbedaan hasil ini (yield gap) secara garis besar disebabkan oleh dua faktor yaitu faktor non-teknis dan faktor teknis. Faktor non-teknis yaitu keadaan yang menghalangi petani untuk menggunakan teknologi yang direkomendasikan. Hal-hal tersebut meliputi: (i) pengetahuan petani sebagai indikatornya adalah pengalaman petani dalam berusahatani, (ii) prasarana transportasi sebagai indikatornya adalah jarak lahan garapan dengan tempat tinggal petani (Laksmi, 2012). Oleh sebab itu penelitian ini sangat penting untuk dilakukan guna mengetahui seberapa besar hasil pendapatan bersih usahatani padi di Kabupaten Langkat.

\section{METODE PENELITIAN}

Penelitian ini dilaksanakan di Kabupaten Langkat. Penelitian ini dimulai bulan Mei 2017 sampai bulan Juni 2017. Pengambilan sampel dilakukan secara acak sederhana (Simple random sampling) yaitu dari 23 Kecamatan, dipilih secara sengaja 3 Kecamatan yang dianggap dapat mewakili Kecamatan setiap usahatani di Kabupaten Langkat. Dari 3 Kecamatan (Kecamatan Secanggang, Kecamatan Sei Bingei, dan Kecamatan Batang Serangan) masing-masing diambil sampel sebanyak 16 kelompok tani.

Data primer dan sekunder digunakan dalam penelitian ini. Data primer didapatkan secara langsung di lapangan, melalui pengamatan serta wawancara langsung dengan petani responden menggunakan panduan kuisioner yang telah disiapkan sebelumnya. Data sekunder adalah sumber data pendukung data-data primer diperoleh dari instansiinstansi terkait seperti Balai Pusat Statistika, Dinas Pertanian Kabupaten Langkat, dan instansi-instansi terkait lainnya. Data sekunder juga diperoleh melalui beberapa literatur yang berasal dari buku, internet serta hasil penelitian terdahulu yang terkait dengan penelitian yang dilakukan.

Teknik analisis data yang digunakan untuk mengetahui tingkat pendapatan petani dilakukan dengan metode deskriptif. Metode ini digunakan untuk mengetahui dan menghitung biaya, penerimaan, pendapatan usahatani padi sawah di daerah penelitian. Untuk melihat ada tidaknya perbedaan pendapatan petani di 3 kecamatan tersebut digunakan uji F. Metode ini digunakan untuk mengetahui perbandingan hasil pendapatan usahatani padi sawah antar Kecamatan di daerah penelitian.

Total biaya usahatani dihitung berdasarkan rumus yang dikemukakan oleh Sukirno (2006), sebagai berikut: 
$\mathrm{TC}=\mathrm{TFC}+\mathrm{TVC}$

Keterangan :

$\mathrm{TC}$ : total biaya/total cost usahatani (Rp)

TFC : total biaya tetap/total fixed cost (Rp)

TVC : total biaya variabel/total variable cost (Rp)

Penerimaan usaha penangkaran benih padi adalah hasil perkalian antara jumlah keseluruhan hasil fisik yang diperoleh dikalikan dengan harganya masing-masing. Rumus penerimaan menurut Rosyidi (2004), sebagai berikut:

$\mathrm{TR}=\mathrm{P} \cdot \mathrm{Q}$

Keterangan :

TR : total penerimaan/total revenue (Rp kg- 1)

$\mathrm{P}$ : harga/price (Rp)

$\mathrm{Q}$ : jumlah produk/quantity $(\mathrm{kg})$

Pendapatan penangkaran benih merupakan selisih antara penerimaan dengan biaya yang dikeluarkan oleh penangkar benih padi selama satu musim tanam. Rumus Pendapatan menurut Boediono (2002) sebagai berikut :

$\mathrm{I}=\mathrm{TR}-\mathrm{TC}$

Keterangan :

I : pendapatan/income (Rp)

$\mathrm{TR}$ : total penerimaan/total revenue $(\mathrm{Rp})$

$\mathrm{TC}$ : total pendapatan/total cost $(\mathrm{Rp})$

$\mathrm{R} / \mathrm{C}$ ratio yaitu adalah jumlah ratio yang dipakai guna melihat keuntungan relatif yang nantinya akan diperoleh pada sebuah proyek atau sebuah usaha. Sebenarnya sebuah proyek akan dikatakan layak dijalankan jika nilai $\mathrm{R} / \mathrm{C}$ yang diperoleh tersebut dinyatakan lebih besar dari 1 . Hal tersebut dapat terjadi sebab, jika nilai R/C semakin tinggi, maka tingkat keuntungan yang diperoleh dalam suatu proyek bisa menjadi lebih tinggi. Penggunaan $\mathrm{R} / \mathrm{C}$ ratio ini diketahui bertujuan untuk mengetahui sejauh mana hasil yang diperoleh dari usaha yang menguntungkan pada periode tertentu.

Rumus R/C Ratio ialah ;

$\mathrm{R} / \mathrm{C}=\mathrm{TR} / \mathrm{TC}$

$\mathrm{R} / \mathrm{C}$ Ratio $=$ Penerimaan $:$ Total Biaya $($ Tetap + Variabel $)$

Keterangan :

TR : total penerimaan/total revenue (Rp)

$\mathrm{TC}$ : total pendapatan/total cost (Rp)

Kriteria :

Jika $\mathrm{R} / \mathrm{C}>1$ dinyatakan untung,

Jika $\mathrm{R} / \mathrm{C}<1$ dinyatakan merugi.

Jika $\mathrm{R} / \mathrm{C}=1$ dinyatakan impas

Uji statistik $\mathrm{F}$ pada dasarnya menunjukkan apakah semua variabel bebas yang dimasukkan dalam model mempunyai pengaruh secara bersama-sama terhadap variabel terikat. Artinya apakah semua variabel penjelas secara bersamaan merupakan variabelvariabel penjelas yang signifikan atau tidak signifikan terhadap variabel dependennya. Secara statistik formulasi uji F adalah (Hidayat A, 2017). 


$$
F=\frac{R^{2} /(k-1)}{\left(1-R^{2}\right) /(n-k)}
$$

Keterangan :

$\mathrm{R}^{2}=$ koefisien determinasi

$\mathrm{k}=$ jumlah variabel bebas

$\mathrm{n} \quad=\quad$ jumlah sampel

kriteria uji :

F-hitung > F-tabel (k-1, n-k), maka tolak H0

F-hitung < F-tabel (k-1, n-k), maka tolak H1

Apabila F-hitung > F-tabel maka secara bersama-sama variabel bebas dalam proses produksi mempunyai pengaruh yang nyata terhadap produksi.

Apabila F-hitung < F-tabel maka secara bersama-sama variabel bebas dalam proses produksi tidak berpengaruh secara nyata terhadap produksi

\section{HASIL DAN PEMBAHASAN}

Pendapatan Usahatani Padi Sawah Di Kabupaten Langkat

Adapun pendapatan usahatani padi sawah di Kabupaten Langkat dihitung berdasarkan penerimaan usahatani padi sawah dikurangi dengan biaya produksi yang digunakan. Luas lahan padi sawah akan mempengaruhi produksi padi sawah pada Kecamatan Secanggang, Kecamatan Sei Bingei, dan Kecamatan Batang Serangan Kabupaten Langkat. Secara teori, semakin luas lahan yang diusahakan petani maka akan meningkatkan produksi tanaman. Luas lahan padi sawah di Kecamatan Secanggang Kabupaten Langkat yang memiliki luas lahan terluas yaitu lebih besar atau sama dengan 21 hektar sebanyak 16 kelompok tani padi sawah. Untuk luas lahan $1-5$ hektar, $6-10$ hektar, $11-15$ hektar, dan $16-20$ hektar tidak ada kelompok tani padi sawah yang memilikinya. Dengan jumlah luas lahan yang semangkin luas tentunya produksi padi sawah juga semangkin tinggi. Luas lahan padi sawah di Kecamatan Sei Bingei Kabupaten Langkat yang memiliki luas lahan terluas yaitu 11 - 15 hektar sebanyak 8 kelompok tani padi sawah. Untuk luas lahan $16-20$ hektar sebanyak 5 kelompok tani padi sawah, dan lebih luas atau sama dengan 21 hektar ada 3 orang kelompok tani padi sawah, sementara luas lahan 1 - 5 hektar, dan 6 - 10 hektar tidak ada petani padi yang memilikinya.

Lluas lahan padi sawah di Kecamatan Batang Serangan Kabupaten Langkat yang memiliki luas lahan terluas yaitu $6-10$ hektar sebanyak 9 kelompok tani padi sawah. Untuk luas lahan 1 - 5 hektar sebanyak 4 kelompok tani padi sawah, dan luas lahan 11 15 hektar ada 3 kelompok tani padi sawah. Untuk luas lahan lebih luas atau sama dengan 21 hektar dan 16 - 20 hektar tidak ada kelompok tani padi yang memilikinya.

Produksi padi sawah di Kecamatan Secanggang Kabupaten Langkat adalah 6356.5 ton dengan rata-rata produksinya sebesar 397.28 ton. Untuk data total produktifitasnya 169.4491 ton dengan rata-rata produktifitasnya adalah 10.5906 ton/ha.

Rata-rata produksi tertinggi terdapat pada Kecamatan Secanggang dengan rata-rata produksi 397.28 ton. Setelah Kecamatan Secanggang adalah Kecamatan Sei Bingei 
dengan rata-rata produksi 277.71 ton. Untuk terendah adalah Kecamatan Batang Serangan dengan rata-rata produksi 80.09 ton.

Untuk rata-rata produktifitas tanaman padi sawah tertinggi adalah Kecamatan Sei Bingei dengan produktifitas rata-rata adalah 16.4673 ton/ha. Setelah itu disusul Kecamatan Batang Serangan dengan produktifitas rata-rata 10.8594 ton/ha. Yang paling rendah adalah Kecamatan Secanggang dengan produktifitas rata-rata adalah 10.5906 ton/ha

Biaya produksi terdiri dari biaya tetap dan biaya tidak tetap. Biaya tetap adalah pengeluaran usahatani yang tidak bergantung kepada besarnya produksi, sedangkan biaya tidak tetap adalah merupakan pengeluaran usahatani yang digunakan untuk tanaman tertentu dan jumlahnya berubah seiring besarnya produksi yang dilakukan.

Total biaya (biaya tidak tetap dan biaya tetap) usahatani padi sawah di Kecamatan Secanggang, Sei Bingei, dan Kecamatan Batang Serangan Kabupaten Langkat dapat dilihat pada Tabel 1.

Tabel 1. Rekapitulasi Rata-rata Biaya (Rp/ha) Usahatani Padi Sawah Di Kecamatan Secanggang, Sei Bingei, dan Batang Serangan Kabupaten Langkat

\begin{tabular}{lll}
\hline No & Kecamatan & Rata-rata Biaya $(\mathrm{Rp} / \mathrm{ha})$ \\
\hline 1 & Secanggang & $2,109,156$ \\
2 & Sei Bingei & $2,200,473$ \\
3 & Batang Serangan & $2,201,407$ \\
\hline
\end{tabular}

Sumber Data Primer (diolah), 2019

Dari Tabel 1 tersebut di atas terlihat bahwa rata-rata biaya yang tertinggi pengeluarannya dalam usahatani padi sawah terdapat pada Kecamatan Batang Serangan sebesar Rp. 2,201,497,-/ha per musim, setelah itu baru Kecamatan Sei Bingei sebesar Rp. 2,200,473,-/ha per musim. Untuk Kecamatan Secanggang tingkat pengeluaran terendah dengan total biaya sebesar Rp. 2,109,156,-/ha per musim

Penerimaan usahatani padi sawah di Kecamatan Secamggang, Kecamatan Sei Bingei, dan Kecamatan Batang Serangan Kbapaten Langkat dapat dilihat pada Tabel 2.

Tabel 2. Rekapitulasi Rata-Rata Penerimaan (Rp/ha) Usahatani Padi Sawah Di Kecamatan Secanggang, Sei Bingei, dan Batang Serangan Kabupaten Langkat

\begin{tabular}{llc}
\hline No & Kecamatan & Penerimaan (Rp/ha) \\
\hline 1 & Secanggang & $95,315,123$ \\
2 & Sei Bingei & $148,206,062$ \\
3 & Batang Serangan & $97,734,580$ \\
\hline
\end{tabular}

Sumber : Data Primer (diolah), 2019

Dari Tabel 2 dapat dijelaskan bahwa penerimaan tertinggi dalam usahatani padi sawah terdapat di Kecamatan Sei Bingei dengan penerimaan yaitu Rp. 148,206,062,-/ha per musim. Berikutnya Kecamatan Batang Serangan dengan penerimaan sebesar Rp. $97,734,580,-$ /ha per musim, dan untuk penerimaan terendah dalam usahatani padi 
sawah di Kecamatan Secanggang dengan penerimaan sebesar Rp. 95,315,124,-/ha per musim.

Pendapatan usahatani padi sawah di Kecamatan Secamggang, Kecamatan Sei Bingei, dan Kecamatan Batang Serangan dapat dilihat pada Tabel 8.

Tabel 3. Rekapitulasi Rata-rata Pendapatan (Rp/ha) Usahatani Padi Sawah Di Kecamatan Secanggang, Sei Bingei, dan Batang Serangan Kabupaten Langkat

\begin{tabular}{lll}
\hline No & Kecamatan & Pendapatan $(\mathrm{Rp} / \mathrm{ha})$ \\
\hline 1 & Secanggang & $93,205,966$ \\
2 & Sei Bingei & $146,005,589$ \\
3 & Batang Serangan & $95,533,174$ \\
\hline
\end{tabular}

Sumber : Data Primer (diolah), 2019

Analisa Imbangan Penerimaan dan Biaya (R/C Ratio)

Analisa R/C ratio tujuannya adalah untuk mengetahui penerimaan dan biaya usaha tanaman padi yang dilakukan oleh petani pada Kecamatan Secanggang, Kecamatan Sei Bingei, dan Kecamatan Batang Serangan Kabupaten Langkat pada periode satu musim tanam dapat dilihat pada Tabel 4.

Tabel 4. Rekapitulasi Rata-rata R/C Ratio Usahatani Padi Sawah di Kecamatan Secanggang, Sei Bingei, dan Batang Serangan Kabupaten Langkat

\begin{tabular}{lll}
\hline No & Kecamatan & R/C Ratio \\
\hline 1 & Secanggang & 1.0226 \\
2 & Sei Bingei & 1.0153 \\
3 & Batang Serangan & 1.0230 \\
\hline
\end{tabular}

Sumber : Data Primer (diolah), 2019

Dari Tabel 4 tersebut dapat dijelaskan bahwa dari ke tiga Kecamatan tersebut (Kecamatan Secanggang, Kecamatan Sei Bingei, dan Kecamatan Batang Serangan), bahwa rata-rata $\mathrm{R} / \mathrm{C}$ ratio tertinggi terdapat pada Kecamatan Batang Serangan dengan $\mathrm{R} / \mathrm{C}$ ratio rata-rata sebesar 1,0230 disusul oleh Kecamatan Secanggang dengan R/C ratio rata-rata sebesar 1,0226 dan terakhir Kecamatan Sei Bingei dengan R/C ratio rata-rata sebesar 1,0153. Dengan demikian adanya perbedaan $\mathrm{R} / \mathrm{C}$ ratio usahatani padi sawah

Hal ini tidak sesuai dengan hasil analisa biaya, penerimaan, dan pendapatan masing-masing kecamatan. Untuk analisa usahatani padi yang meliputi biaya, penerimaan, dan pendapatan. Rata-rata biaya usahatani padi sawah yang tertinggi adalah Kecamatan Batang Serangan, dimana untuk rata-rata total biaya yang dikeluarkan sebesar Rp. 2,201,407,-/ha per musim tanam. Untuk rata-rata total penerimaan usahatani padi sawah yang tertinggi terdapat pada Kecamatan Sei Bingei yaitu sebesar Rp. 148,206,062,-/ha per musim tanam. Untuk rata-rata total pendapatan tertinggi terdapat pada Kecamatan Sei Bingei yaitu sebesar Rp. 146,005,589,-/ha per musim tanam.

Uji-F digunakan untuk menunjukkan apakah keseluruhan variabel independen berpengaruh terhadap variabel dependen. Nilai statistik F menunjukkan bahwa secara 
bersama-sama berpengaruh secara positif dan signifikan dari variabel bebas yaitu $\mathrm{X}$ berupa biaya, penerimaan terhadap variabel terikat pendapatan $(\mathrm{Y})$ usahatani padi sawah di Kabupaten Langkat.

Bahwa usahatani padi sawah diperoleh F-hitung 36,244 dimana F-tabel diperoleh angka 4,60 lebih kecil dari F-hitung dan untuk angka signifikan diperoleh angka 0.000 lebih kecil dari signifikan $0.05(36,244>4,60$ dan $0,000<0,05)$ yang berarti menolak hipotesis H0 dan H1 diterima. Sehingga dapat diartikan bahwa secara analisis keseluruhan terdapat perbedaan signifikan hasil usahatani padi sawah antar Kecamatan di Kabupaten Langkat.

Lebih jelasnya untuk mengetahui perbedaan pendapatan antar Kecamatan di Kabupaten Langkat dilakukan dengan uji jarak Duncant. Dari hasil uji jarak Duncant didapat pendapatan yang teringgi terdapat pada Kecamatan Sei Bingei yaitu Rp. $146,005,589,-/$ ha yang berbeda sangat nyata dengan Kecamatan Secanggang yaitu Rp. 93,205,966,-/ha dan Kecamatan Batang Serangan yaitu Rp. 95,533,174,-/ha. Untuk Kecamatan Batang Serangan berbeda sangat nyata dengan Kecamatan Secanggang. Lebih jelasnya perbedaan pendapatan usahatani padi sawah antar Kecamatan Secanggang, Sei Bingei, dan Kecamatan Batang Serangan di Kabupaten Langkat dapat dilihat pada Tabel 5.

Tabel 5. Uji Beda Rata-rata Pendapatan (Rp) Antar Kecamatan di Kabupaten Langkat

\begin{tabular}{clcccc}
\hline No & Kecamatan & Rata & Rata & Notasi & \\
& & Pendapatan & & $5 \%$ & $\%$ \\
\hline 1 & Secanggang & $93,205,966$ & $\mathrm{c}$ & $\mathrm{C}$ \\
2 & Sei Bingei & $146,005,589$ & $\mathrm{a}$ & $\mathrm{A}$ \\
3 & Batang Serangan & $95,533,174$ & $\mathrm{~b}$ & $\mathrm{~B}$ \\
\hline
\end{tabular}

Keterangan : Angka-angka pada kolom yang sama yang diikuti oleh huruf yang tidak sama berarti berbeda nyata pada taraf $5 \%$ (huruf kecil) dan berbeda sangat nyata pada taraf $1 \%$.

\section{SIMPULAN}

Hasil penelitian menunjukkan rata-rata biaya yang tertinggi pengeluarannya dalam usahatani padi sawah terdapat pada Kecamatan Batang Serangan kemudian Kecamatan Sei Bingei dan terakhir Kecamatan Secanggang. Penerimaan tertinggi dalam usahatani padi sawah terdapat di Kecamatan Sei Bingei selanjutnya Kecamatan Batang dan untuk penerimaan terendah dalam usahatani padi sawah di Kecamatan Secanggang.

Hasil analisis kelayakan usahatani dengan metode R/C menunjukkan bahwa ketiga kecamatan layak dengan hasil rasio kelayakan tertinggi adalah Kecamatan Batang Serangan dan kemudian Kecamatan Secanggang dan terakhir Kecamatan Sei Bingei. Dari hasil uji jarak Duncant terdapat perbedaan pendapatan yang sangat nyata antara Kecamatan Sei Bingei dengan Kecamatan Batang Serangan maupun dengan Kecamatan Secanggang di Kabupaten Langkat.

Saran untuk usahatani padi sawah khususnya di Kecamatan Secanggang, dan Kecamatan Batang Serangan, untuk dapat meningkatkan potensi dalam melakukan 
penanaman dan perawatan dengan cara menggunakan alat teknologi untuk meningkatkan tingkat pendapatan keluarga. Kepada pemerintah, lebih memperhatikan Kecamatan Secanggang, dan Kecamatan Batang Serangan yang tingkat pendapatannya lebih rendah dalam usahatani padi sawah. Kepada dunia pendidikan khusus perguruan tinggi, selanjutnya agar dilakukan penelitian lanjutan dan lebih mendalam.

\section{DAFTAR PUSTAKA}

Ambarsari, (2014). Analisis Pendapatan dan Penerimaan Usaha Tani Padi (Oryza sativa L) di Kabupaten Indramayu. Jurnal Ilmiah Pertanian. Universitas Wiralodra. Bandung.

Boediono, (2002). Mikro Ekonomi : Seri Sinopsis Pengantar Ilmu Eknomi. No.1 Edisi Kedua. Cetakan Kedua. BPEE. Yogyakarta.

BPT Pertanian. (2009). Laporan Tahunan. Departemen Sumatera Utara. Medan

Badan Pusat Statistik (2017). Data Statsitik Sumatera Utara Tahun 2017. Sumatera Utara. Medan

Badan Pusat Statistik Kabupaten Langkat. (2016). Data Statistik Kabupaten Langkat Tahun 2016. Langkat.

Dewi N. L. P. K, (2016). Analisis Tingkat Keuntungan Usahatani Padi Sawah Sebagai Dampak Dari Adanya Subsidi Pupuk di Kabupaten Tabanan. Jurnal Ilmu Pertanian.

Hidayat Anwar. (2017). Statiskian. Penerbit Erlangga. Jakarta.

Laksmi. (2012). Metode Penelitian. Penerbit Pustaka Pelajar. Yogyakarta.

Lestari. (2012). Studi Kualitatif. Jurnal Ilmu Pertnian. Jurnal Ilmu Pertnaian. Universitas Muhammadiyah Surakarta. Semarang.

Nuraini. (2016). Statistik Indonesia. Jurnal Ilmu Pertanian. Badan Pusat Statistik Indonesia dan Direktorat Jenderal Hortikultura. Jakarta.

Roidah. (2015). Analisis Pendapatan Usaha Tani Padi Musim Hujan dan Musim Kemarau (Studi Kasus Di Desa Sepatan Kecamatan Gondang Kabupaten Tulungagung. Jurnal Ilmu Pertanian. Universitas Tulungagung.

Rosyidi. (2004). Pengantar Ilmu Pertanian. PT. Rineka Cipta. Jakarta.

Supartama. (2013). Analisis Pendapatan dan Kelayakan Usaha Tani Padi Sawah di Subak Baturiti Desa Desa Balinggi Kecamatan Balinggi Kabupaten Parigi Moutong. Jurnal Ilmu Pertanian. Jakarta.

Widayanto. (2007). Pengaruh Rasio Pendapatan Usaha Tani Padi Sawah. Institut Pertanian Bogor.

Widarto dan Susilo. (2004). Introduksi Beberapa Varietas Unggul Baru Padi Gogo Di Kabupaten Blora. Balai Pengkajian Teknologi Pertanian. Jawa Tengah. 